\title{
Reconsidering the role of neuronal intrinsic properties and neuromodulation in vestibular homeostasis
}

\section{Mathieu Beraneck* and Erwin Idoux}

Centre d'Etude de la SensoriMotricité, CNRS UMR 8194, Université Paris Descartes, Sorbonne Paris Cité, Paris, France

\section{Edited by:}

Kenna Peusner, George Washington University, USA

\section{Reviewed by:}

Maurizio Versino, Pavia University, Italy

Aaron Camp, University of Sydney, Australia

\section{*Correspondence:}

Mathieu Beraneck, Centre d'Etude de la SensoriMotricité, CNRS UMR 8194, Université Paris Descartes, Sorbonne Paris Cité, 45 rue des Saints-Pères, 75270 Paris Cedex 06, France. e-mail: mathieu.beraneck@ parisdescartes.fr
The sensorimotor transformations performed by central vestibular neurons constantly adapt as the animal faces conflicting sensory information or sustains injuries. To ensure the homeostasis of vestibular-related functions, neural changes could in part rely on the regulation of $2^{\circ} \mathrm{VN}$ intrinsic properties. Here we review evidence that demonstrates modulation and plasticity of central vestibular neurons' intrinsic properties. We first present the partition of Rodents' vestibular neurons into distinct subtypes, namely type A and type B. Then, we focus on the respective properties of each type, their putative roles in vestibular functions, fast control by neuromodulators and persistent modifications following a lesion. The intrinsic properties of central vestibular neurons can be swiftly modulated by a wealth of neuromodulators to adapt rapidly to temporary changes of ecophysiological surroundings. To illustrate how intrinsic excitability can be rapidly modified in physiological conditions and therefore be therapeutic targets, we present the modulation of vestibular reflexes in relation to the variations of the neuromodulatory inputs during the sleep/wake cycle. On the other hand, intrinsic properties can also be slowly, yet permanently, modified in response to major perturbations, e.g., after unilateral labyrinthectomy (UL). We revisit the experimental evidence, which demonstrates that drastic alterations of the central vestibular neurons' intrinsic properties occur following UL, with a slow time course, more on par with the compensation of dynamic deficits than static ones. Data are interpreted in the framework of distributed processes that progress from global, large-scale coping mechanisms (e.g., changes in behavioral strategies) to local, small-scale ones (e.g., changes in intrinsic properties). Within this framework, the compensation of dynamic deficits improves over time as deeper modifications are engraved within the finer parts of the vestibular-related networks. Finally, we offer perspectives and working hypotheses to pave the way for future research aimed at understanding the modulation and plasticity of central vestibular neurons' intrinsic properties.

Keywords: vestibular compensation, intrinsic properties, central vestibular neurons, postlesional plasticity, neuromodulation

\section{INTRODUCTION}

The accurate perception of attitude and motion is essential to stabilize gaze and posture as well as to ensure proper locomotion and navigation (Angelaki and Cullen, 2008). Head-in-space motion detection originates at the level of the vestibular organs, located in the inner ears. Then, the relevant motor commands for vestibular-related reflexes are produced by the central nervous system through sensorimotor transformations merging several sensory modalities into a single frame of reference.

Central vestibular neurons $\left(2^{\circ} \mathrm{VN}\right)$, located in the brainstem, are responsible for the early integration and processing of vestibular, visual, and proprioceptive inputs. The $2^{\circ} \mathrm{VN}$ integrative properties critically depend on their intrinsic properties, defined as the biophysical properties resulting from the idiosyncratic combination of morphological properties, membrane ionic conductances, and intracellular buffers controlling the ions' concentrations. The intrinsic properties of central vestibular neurons are instrumental in shaping their filtering properties and dynamic computing abilities (Straka et al., 2009; Beraneck and Straka, 2011). In vitro, $2^{\circ} \mathrm{VN}$ form a heterogeneous population which can be partitioned into several archetypes, as the properties of these neurons differ both between types and between related types in different vestibular nuclei (review in Straka et al., 2005).

Throughout an animal's lifespan, central vestibular neurons sensorimotor transformations need to constantly adapt to body growth, to environmental changes, to sensory conflict, and to injuries. In order to ensure the homeostasis of vestibular reflexes and vestibular-related functions, changes have to occur within the vestibular system to maintain a relevant output, and such plasticity could rely on the regulation of $2^{\circ} \mathrm{VN}$ intrinsic properties. Depending on the initial trigger, different kinds of plasticities will affect the excitability, the filtering properties, or other dynamical aspects of $2^{\circ} \mathrm{VN}$ 's processing abilities with variable time courses and persistency.

Here, we review in vitro evidence that demonstrates that neuronal intrinsic properties can be both swiftly modified by a wealth 
of neuromodulators (e.g., to adapt rapidly to temporary changes of the ecophysiological surroundings) and slowly, yet deeply, set to new values to compensate for the permanent loss of vestibular inputs. In particular, we discuss the experimental data about the persistent alteration of the electrophysiological identity of $2^{\circ}$ VN during vestibular compensation. We then offer interpretations and future research axes likely to shed light on the plastic processes underlying modifications of $2^{\circ} \mathrm{VN}$ intrinsic properties.

\section{DESCRIPTION OF $2^{\circ}$ VN BASIC INTRINSIC PROPERTIES}

Following Llinás' (1988) definition, intrinsic properties are the electroresponsive properties that give neurons their pacemaker activity, basic excitability, and resonance, in the absence of synaptic stimulation or neuromodulation.

The $2^{\circ} \mathrm{VN}$ are characterized by their intrinsic pacemaker activity in slices (Serafin et al., 1991a; Johnston et al., 1994; Darlington et al., 1995), for it persists even under synaptic uncoupling conditions. This synaptic uncoupling can be achieved by modifying the artificial cerebro-spinal fluid (ACSF), e.g., with high $\mathrm{Mg}^{2+} / \mathrm{low}$ $\mathrm{Ca}^{2+}$ ACSF (Vibert et al., 2000; Darlington et al., 2002), or with a cocktail of synaptic blockers (Ris et al., 2001a; Guilding and Dutia, 2005) as well as by complete isolation from other structures (Darlington and Smith, 2000). The $2^{\circ} \mathrm{VN}$ intrinsic properties, and in particular those of neurons from the medial vestibular nucleus, have been described in many Vertebrates, including Rats (Gallagher et al., 1985; Johnston et al., 1994), Mice (Dutia et al., 1995; Johnston and Dutia, 1996), Guinea pigs (Serafin et al., 1991a,b), Amphibians (Straka et al., 2004), and Chicks (du Lac and Lisberger, 1995; Gottesman-Davis and Peusner, 2010; Gottesman-Davis et al., 2011). In all Vertebrates, medial $2^{\circ} \mathrm{VN}$ form a heterogeneous population dominated by tonic and phasic neurons (Straka et al., 2005; Eugène et al., 2007; Grassi et al., 2009; Camp et al., 2010). In Rodents, these two canonical subtypes are electrophysiologically equivalent to type A and type B neurons (respectively tonic and phasico-tonic neurons, Straka et al., 2009; Beraneck and Straka, 2011). Type A and type B neurons differ in several membrane ionic conductances that are responsible for the differences in spike shapes, discharge dynamics, and resonance frequencies (Ris et al., 2001b; Straka et al., 2005 for review).

The methods to classify neurons into type A and type B subsets have been a matter of debate. Because the electrophysiological signature of a neuron can vary depending on recording conditions, qualitative categorization using the bare eye proved biased. In addition, type $\mathrm{A}$ and type $\mathrm{B} 2^{\circ} \mathrm{VN}$ neurons were thought to represent canonical endpoints of a functional continuum (du $\mathrm{Lac}$ and Lisberger, 1995) rather than different subtypes. However, to prevent misclassification, and to be able to compare the intrinsic membrane properties of $2^{\circ} \mathrm{VN}$ recorded in physiological or pathological situations, we developed a quantitative analysis and classification methodology based on the neurons' spike shape (see Beraneck et al., 2003). This method holds across species and even works without a priori requirements regarding the number of classes or thresholds for the parameters using an expectationmaximization algorithm (see Idoux et al., 2008). Several reviews already have summarized these classifications, so readers interested in more detailed descriptions of type $\mathrm{A} / \mathrm{B}$ categorization can refer to Straka et al. (2005) or Eugène et al. (2011).
Briefly, type A neurons are characterized in vitro by a deep monophasic afterhyperpolarization at rest, have a stable spontaneous activity and respond linearly when probed with dynamic stimuli such as ramps, sine waves, or white noise (Figure 1). Type A would correspond to the most "regular" tonic neurons identified in vivo (Beraneck et al., 2004; Straka et al., 2005). Type B neurons are characterized by a biphasic afterhyperpolarization, show more non-linear responses and are more sensitive to current injection. A subset of type B neurons displays low-threshold spikes, which suggest that type $\mathrm{B}$ neurons constitute a heterogeneous population (Serafin et al., 1990, 1991b). Overall, the type B neurons likely correspond to irregular phasic neurons identified in vivo (Babalian et al., 1997; Ris et al., 2001b; Straka et al., 2005).

\section{INSERTION OF CENTRAL VESTIBULAR NEURONS INTO LOCAL NETWORKS}

The relationship between intrinsic properties and network properties has recently been investigated in the frog isolated whole-brain preparation (Biesdorf et al., 2008; Pfanzelt et al., 2008). The intrinsic properties of a given neuron are roughly matched by the synaptic activity of the neural network in which the neurons are embedded (Beraneck et al., 2007; Pfanzelt et al., 2008; Beraneck and Straka, 2011; Rössert and Straka, 2011; Rössert et al., 2011), thus facilitating the creation of separate sets of neuronal filters for different stimulus frequency ranges. Recent studies have clarified the differential neurochemical content, projections, and insertions in local networks of type A and type B neurons, even though the debate is not settled yet (see Eugène et al., 2011 for review).

Based on their neurotransmitter content, the majority of type A neurons appear to be GABAergic neurons (Takazawa, 2004; Bagnall et al., 2007), while type B neurons could be either glutamatergic, glycinergic, or GABAergic neurons (Takazawa, 2004; Bagnall et al., 2007). However, the type A/B classification only partially overlaps with the partition along neurotransmitter content. Furthermore, both types receive direct excitatory vestibular inputs and are targeted by commissural inhibition (Babalian et al., 1997).

In addition, type $\mathrm{A}$ neurons appear to be more homogeneous than type B neurons. These GABAergic type A neurons seem to be exclusively involved in inhibitory local circuits (Shin et al., 2011). Their inhibitory inputs, including sparse floccular inputs (Shin et al., 2011), are almost exclusively GABAergic as well (Camp et al., 2006). Therefore, it seems likely that type A neurons are mainly involved in the regulation of the bilateral activity of the vestibular nuclei and are a major component of the commissural system: they could represent the majority of the local interneurons (Takazawa, 2004), and presumably correspond in vivo to most of the type II neurons (Shimazu and Precht, 1965). This hypothesis has yet to be experimentally confirmed.

On the other hand, type B neurons could serve as projection neurons, i.e., convey the excitatory glutamatergic or inhibitory glycinergic output of the vestibular nuclei. The glycinergic type B neurons subset is the most densely contacted by GABAergic inputs, from both floccular (Shin et al., 2011) and probably commissural origin (Camp et al., 2006).

In summary, readers should bear in mind that type A and type $\mathrm{B}$ categories are based on the electrophysiological signatures at rest and not on particular connectivity. However, each type of 


\section{A Static PROperties}

MVN Type A

-Spontaneously active -Single, deep AHP

$-I_{A}$-like rectification

-Wide action potential

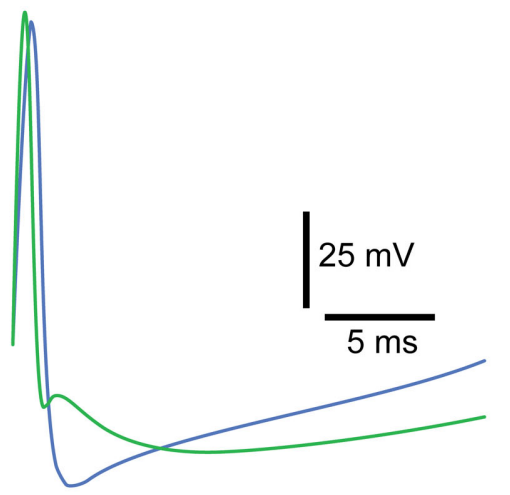

B

DYNAMIC PROPERTIES

$\rightarrow$ RAMPS

- Linear response to ramp stimulations (no overshoot)

C

DYNAMIC PROPERTIES

$\rightarrow$ SINE WAVES

-Mild resonance around $8 \mathrm{~Hz}$
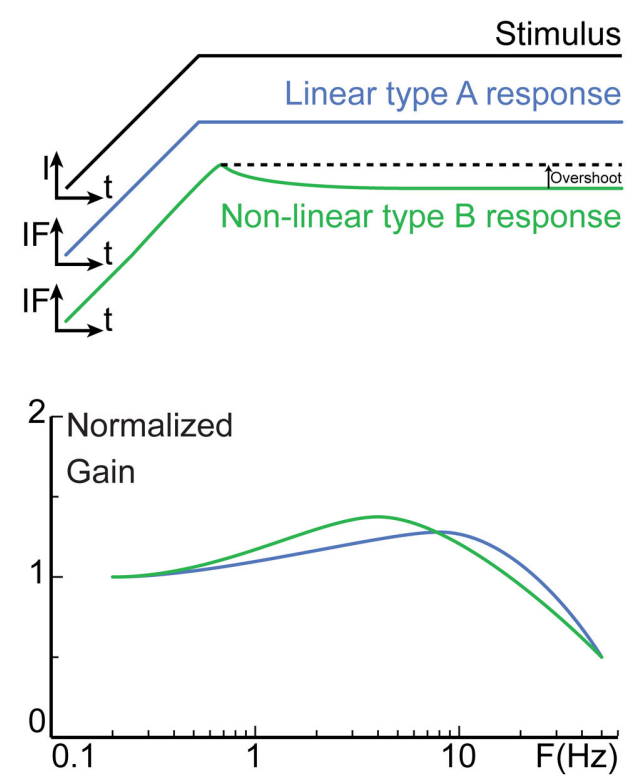

MVN Type B

-Spontaneously active

-Double AHP

-No I -like rectification

-Thin action potential

\section{-Non-linear response to ramp stimulations (overshoot)}

FIGURE 1 | Basic intrinsic membrane properties of type $A$ versus type B medial $2^{\circ}$ VN (MVN). (A) Static properties of MVN. Superimposed averaged spike traces illustrate the differences in the electrophysiological signatures of type A (blue traces) and type B (green traces) neurons. The most salient characteristics such as the differences in the

afterhyperpolarization are summarized. Transient $\mathrm{A}$-type $\mathrm{K}^{+}$channels $\left(\mathrm{I}_{A}\right)$ in neurons are implicated in the delay of the spike onset and the decrease in the firing frequency. (B) and (C), dynamic properties of MVN. (B) In response to ramps of currents (/), type $A$ neurons show linear firing responses, while most type $B$ neurons display a non-linear overshoot in their instantaneous frequency (IF). Similarly, when stimulated with sine waves of current (C), the transfer functions of type $A$ and $B$ neurons differs, type $A$ neurons showing less of a resonance but at higher frequency than type $B$ neurons; $t$, time. F, stimulation frequency. neuron is differentially inserted in vestibular-related networks. The basic framework we will use to analyze the subsequent data can be described as such: type A neurons mostly correspond to tonic cells involved in inhibitory, local networks, while most type $\mathrm{B}$ would constitute the phasico-tonic excitatory or inhibitory output of the vestibular networks (Biesdorf et al., 2008; Rössert et al., 2011).

\section{NEUROMODULATION OF CENTRAL VESTIBULAR NEURONS EFFECT OF NEUROMODULATION ON MEMBRANE PROPERTIES IN VITRO AND IN VIVO}

The $2^{\circ} \mathrm{VN}$ not only receive direct synaptic inputs from the vestibular organs, but also from networks involved in autonomic functions and diffuse neuromodulatory systems. The activity of these systems depends on many internal and external factors such as the arousal state, including the circadian sleep/wake alternation, or the perception of a potential threat. For example, when the animal is asleep, the sympathetic activity is decreased while the parasympathetic activity is increased (Chokroverty, 2010). These changes in the autonomous nervous system mimic the changes in the respective concentration of noradrenaline (NAd) and acetylcholine (ACh) in the central nervous system, vestibular nuclei included. The neuromodulation of the properties of $2^{\circ}$ $\mathrm{VN}$ is also particularly important in clinic, as many agonists and antagonists of monoamines and ACh receptors are used against motion sickness (Takeda et al., 2001), vertigos (Rascol et al., 1995), or during vestibular compensation (Tighilet and Lacour, 1997). In addition, the vestibular system is embedded into numerous physiological loops (e.g., coeruleo-vestibular and raphe-vestibular networks, see below) as illustrated by the prevalent comorbidity of 
balance disorders and motion sickness with psychiatric disorders, migraine, and anxiety (Teggi et al., 2007; Balaban et al., 2011).

When applied in vitro, dopamine and NAd directly increase the excitability of both type A and B neurons, which is observed as either a depolarization of the resting membrane potential or as an increase of the discharge rate. However, NAd also has the opposite effect on a small number of neurons (Podda et al., 2001) and dopamine regulates GABAergic synapses contacting vestibular neurons (Vibert et al., 1994). Even more complex loops might be involved in vivo as injection of NAd decreases the activity of medial $2^{\circ} \mathrm{VN}$, unlike the direct cellular effect (Kirsten and Sharma, 1976; Tychsen and Sitaram, 1989; Licata et al., 1993). Reciprocal connections between the vestibular neurons and noradrenergic neurons located in the locus coeruleus (Schuerger and Balaban, 1993, 1999; Horowitz et al., 2005) involved in stress responses and in the sleep/wake cycle (Takahashi et al., 2010) make the coeruleovestibular network a candidate for therapeutics of neuro-otologic balance disorders. Vestibular nuclei also receive a serotoninergic input from the raphe nuclei (Halberstadt and Balaban, 2003), implicated as well in the sleep/wake cycle. When applied in vitro, serotonin has a straight depressing effect through $5-\mathrm{HT}_{1 \mathrm{~A}}$ receptors on the firing rate of about $15 \%$ of both type A and type $\mathrm{B}$ neurons. In most cases, however, activation of $5-\mathrm{HT}_{2}$ receptors triggers a decrease followed by an increase in the $2^{\circ} \mathrm{VN}$ resting discharge, as seen in vivo (Licata et al., 1995). In a majority of type B neurons (80\%) and a minority of type A (20\%), these effects are due to post-synaptic receptors as they persist in uncoupling conditions (Vibert et al., 1994).

The most efficient drugs used to treat balance disorders and motion sickness target the histaminergic or the cholinergic systems (Takeda et al., 2001). Histaminergic (Bergquist and Dutia, 2006), nicotinic and muscarinic receptors are indeed found in all vestibular nuclei (Vidal et al., 1999). Histamine and ACh depolarize most of the medial $2^{\circ} \mathrm{VN}$. Detailed analysis of the histaminergic modulation of the medial $2^{\circ} \mathrm{VN}$ neurons can be found in Bergquist et al. (2006) and Bergquist and Dutia (2006). Modulation by ACh persists in synaptic uncoupling conditions (low $\mathrm{Ca}^{2+} / \mathrm{high}_{\mathrm{Mg}}{ }^{2+}$; Phelan and Gallagher, 1992; Sun et al., 2002). Interestingly, ACh acts differently on type A and B (Vibert et al., 1994): while carbachol, nicotine, and muscarine strongly depolarize the majority of type B neurons, they depolarize only half of the type A neurons. Thus, a subset of type A neurons appears to be unresponsive to cholinergic modulation.

In summary, monoamines and ACh receptors constitute a therapeutic target of choice for drugs against motion sickness and balance disorders (Soto and Vega, 2010). Most of the substances have similar effects on type A and type B neurons, however type A neurons were generally found to be slightly less sensitive to neuromodulation than type B neurons (Vibert et al., 1994; de Waele et al., 1995).

\section{PHYSIOLOGICAL MODULATION OF CENTRAL VESTIBULAR NEURONS DURING SLEEP/WAKE CYCLES}

The vestibular nuclei projects to regions thought to be involved in circadian rhythm, stress, and arousal (Yardley et al., 1995; Horowitz et al., 2005): the locus coeruleus, dorsal and pedunculopontine tegmental nuclei, dorsal raphe, and lateral preoptic area.
In addition, $2^{\circ} \mathrm{VN}$ receive projections from the lateral hypothalamic hypocretin neurons involved in wakefulness (Horowitz et al., 2005). To illustrate how intrinsic excitability and vestibular-related functions can rapidly be modified in physiological conditions, we will now present how the vestibulo-ocular reflex (VOR) is modified by neuromodulatory variations in relation to the sleep/wake cycle.

Briefly, the circadian sleep/wake cycle consists of two states (McCarley, 2007; Chokroverty, 2010): wakefulness and sleep. The sleep period comprises two phases, which alternate several times per night: rapid eye movement sleep (REM sleep) and non-rapid eye movement sleep (NREM sleep); the latter is further subdivided into three stages (in the Figure 2A, only the first sequence is depicted in details): $\mathrm{N} 1$ (drowsiness) N2 and N3 (slow wave sleep).

During wakefulness and after REM, the concentrations of NAd, serotonin, and $\mathrm{ACh}$ are high, and rapidly decrease during N1 to reach fairly low concentrations during N3 (Jones, 2005; Miller and O'Callaghan, 2006; McCarley, 2007). As hinted by the drowsiness induced by the first generation of anti-histaminic drugs, histamine is also a key neuromodulator in the sleep/wake cycle (Thakkar, 2011). However, its release cycle is a lot slower than the three others: at high concentration during wakefulness, it quickly decreases throughout the sleep period, and then progressively rebounds while the animal is still sleeping (Mochizuki et al., 1992; Zeitzer et al., 2011).

In parallel to these changes, the performances of the vestibuloocular reflex vary during the nychthemeral cycle. Indeed, during NREM the rapid eye movements (resetting saccades) are absent by definition and the slow compensatory phase of the reflex sees both its spatial and temporal accuracy falter (Figure 2B): on one hand, the gain decreases and on the other hand, the phase significantly deviates from $180^{\circ}$, rendering the reflex less compensatory (Jones and Sugie, 1972; Kasper et al., 1992; Hirata et al., 2009).

At the cellular level, the arousal level also conditions the properties of the neurons in the vestibular nuclei. Because intracellular recordings are particularly challenging in vivo, modifications of the shapes of the spikes during sleep remains unknown. However, in anesthetized Rats, the electrophysiological signatures of type A and type B neurons had the same main features as in vitro (Saito and Ozawa, 2007). In Gerbils, decerebration decreases both the resting discharge and excitability of central vestibular neurons compared to awake animals (Kaufman et al., 2000). In Cats, resting discharge of central vestibular neurons is decreased during drowsiness or slow wave sleep compared to wakefulness. When the transition from NREM to REM sleep occurs, spontaneous discharge of lateral and superior vestibular neurons remains unchanged or slightly increases, whereas the discharge of neurons in the medial and descending nuclei is at least doubled compared to wakefulness and display bursts of activity presumably in synchrony with eye movements (Bizzi et al., 1964).

Hence, during a complete circadian cycle, the resting discharge, and excitability of central vestibular neurons varies according to the arousal state along with the neuromodulatory environment. Such changes can occur in a matter of seconds, as shown by VOR response modifications during transient arousal shifts (Kasper et al., 1992). Neuromodulation therefore constitutes a very rapid and labile tool to shape and adapt the vestibular functions. In 


\section{A}

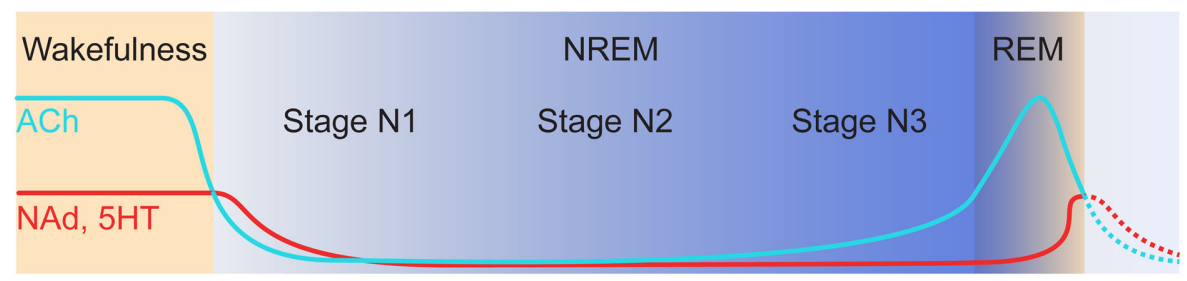

B
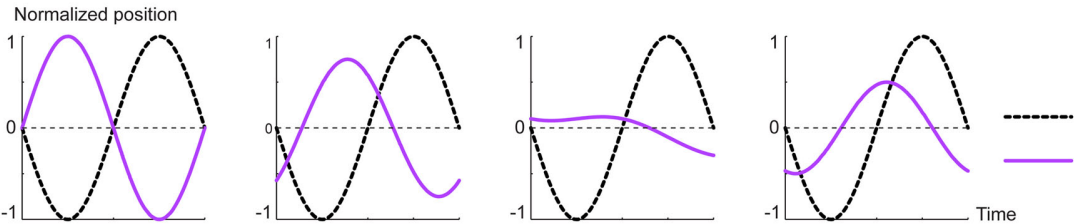

Head
Eye

FIGURE 2 | Physiological changes of neuromodulators during sleep/wake cycle alter vestibular functions. (A) Schematic of the variations of neuromodulatory concentration between wakefulness and the first NREM/REM episode of sleep. ACh, acetylcholine; NAd, Noradrenaline; $5 \mathrm{HT}$, serotonin. (Adapted from McCarley, 2007). (B) Diagram of eye movements in response to head rotations during vestibulo-ocular reflex in dark. Both the amplitude and phase of the eye movements generated in response to sinusoidal stimulations are increasingly altered as deeper levels of sleep are reached. (Adapted from Jones and Sugie, 1972; and Kasper et al., 1992). some pathological situations, however, restoring vestibular functions requires more drastic modifications. That is the case after a unilateral vestibular lesion which induces profound alterations of the $2^{\circ} \mathrm{VN}$ intrinsic properties with a rather slow dynamic.

\section{POSTLESIONAL PLASTICITY INVOLVES MULTIPLE PROCESSES WITH DIFFERENT DYNAMICS \\ BEHAVIORAL CORRELATES OF VESTIBULAR COMPENSATION}

Unilateral labyrinthectomy (UL) and VIIIth-nerve neurectomy trigger major oculomotor and postural disturbances that spontaneously regress (Smith and Curthoys, 1989; Dieringer, 1995; Curthoys, 2000). "Vestibular compensation" refers to the partial resolution of motor deficits observed at rest (static symptoms) or during movements (dynamic symptoms). The static deficits, which include postural distortions and a spontaneous ocular nystagmus, disappear within a few days in most Vertebrates (Smith and Curthoys, 1989; Darlington et al., 2002). On the other hand, the dynamic response of vestibular-driven reflexes recovers progressively yet never completely. In particular, the performance of the VOR in response to movements involving high accelerations remains impaired in the long-term (Guinea pigs: Gilchrist et al., 1998; Mice: Beraneck et al., 2008; review in Cullen et al., 2009).

\section{NEURAL CORRELATES OF COMPENSATION OF THE STATIC SYMPTOMS}

The identification of the neural correlates of vestibular compensation constitutes a challenge for integrative neurosciences, because vestibular compensation is a distributed process (Llinas and Walton, 1979) that involves changes in various nuclei and vestibular-related structures throughout the brain. It questions how the central nervous system deals with major deafferentation, as it is the case during aging, in many neurodegenerative diseases or after strokes (see also Framing Intrinsic Membrane Plasticity in Other Systems).
A UL deprives the ipsilesional $2^{\circ} \mathrm{VN}$ of their main excitatory drive. Their spontaneous discharge disappears by the conjugated effects of this disfacilitation and the increased weight of the commissural inhibition exerted by the contralesional medial $2^{\circ} \mathrm{VN}$ (MVN neurons), which, conversely, see their spontaneous discharge increase as the result of the disinhibition (Ris et al., 1995, 1997). Therefore, the system goes from a balanced state (Figure 3A, "control" state), where both MVN are similarly active, to a situation where the ipsilesional MVN neurons are mostly silent and the contralesional MVN neurons more active (Figure 3B, "acute" state). This imbalance is usually seen as the main cause for the acute static deficits (Smith and Curthoys, 1989). During the first week following UL, the recovery of a normal resting discharge by the deafferented neurons parallels the disappearance of the static symptoms (Ris et al., 1995, 1997).

\section{BECHTEREW AND THE TIME COURSE OF VESTIBULAR COMPENSATION: FROM THE GLOBAL TO THE LOCAL}

The demonstration of the time course of vestibular compensation goes back to Bechterew (1883), who described the effects of consecutive vestibular lesions. The first unilateral lesion (e.g., on the left side) triggers postural deficits that compensate as described above. Once static compensation is achieved, a lesion or an inactivation (Bergquist et al., 2008) of the remaining side (right side) triggers symmetrical symptoms, as if this was the initial lesion. However, this symmetry in the symptoms depends on the time between both lesions: the longer the time, the more symmetrical the symptoms. In Guinea pigs, asymmetrical symptoms are observed when a delay of less than 7 days separates the lesions (Vibert et al., 1999b). The Bechterew's phenomenon demonstrates that cellular events take place to restore balance during the first postlesional week, however with a relatively slow time course.

Discrepancies are demonstrated in vivo between the dynamics of neuronal modifications and behavioral recoveries (Ris et al., 


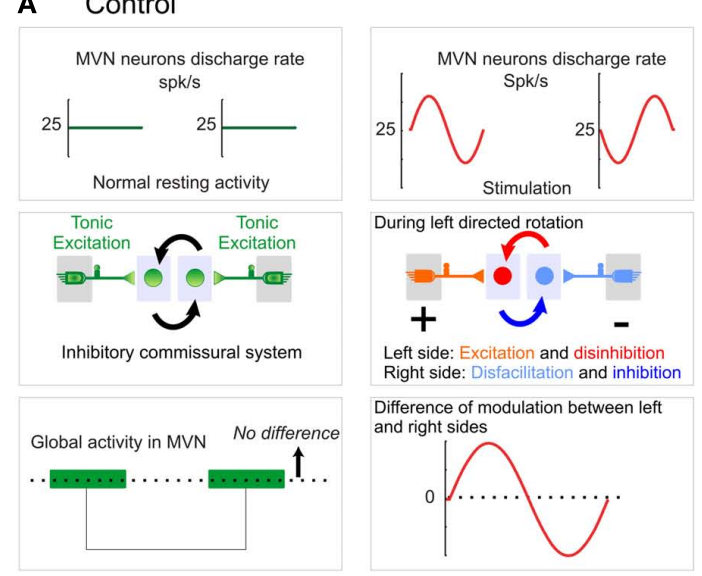

\section{B Acute}
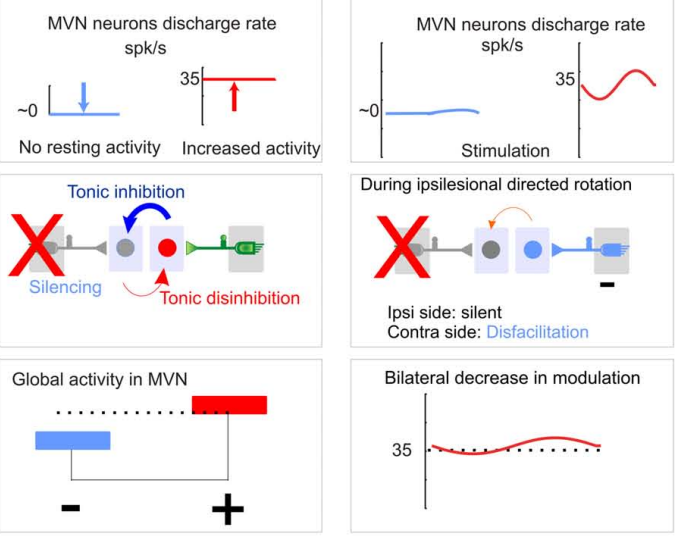

Ipsi side: silent Contra side: Disfacilitation

Bilateral decrease in modulation

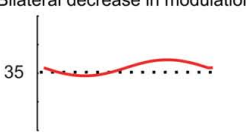

\section{Compensated}

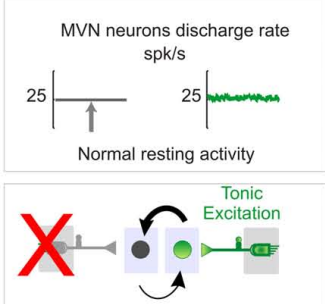

Inhibitory commissural system

Global activity in MVN
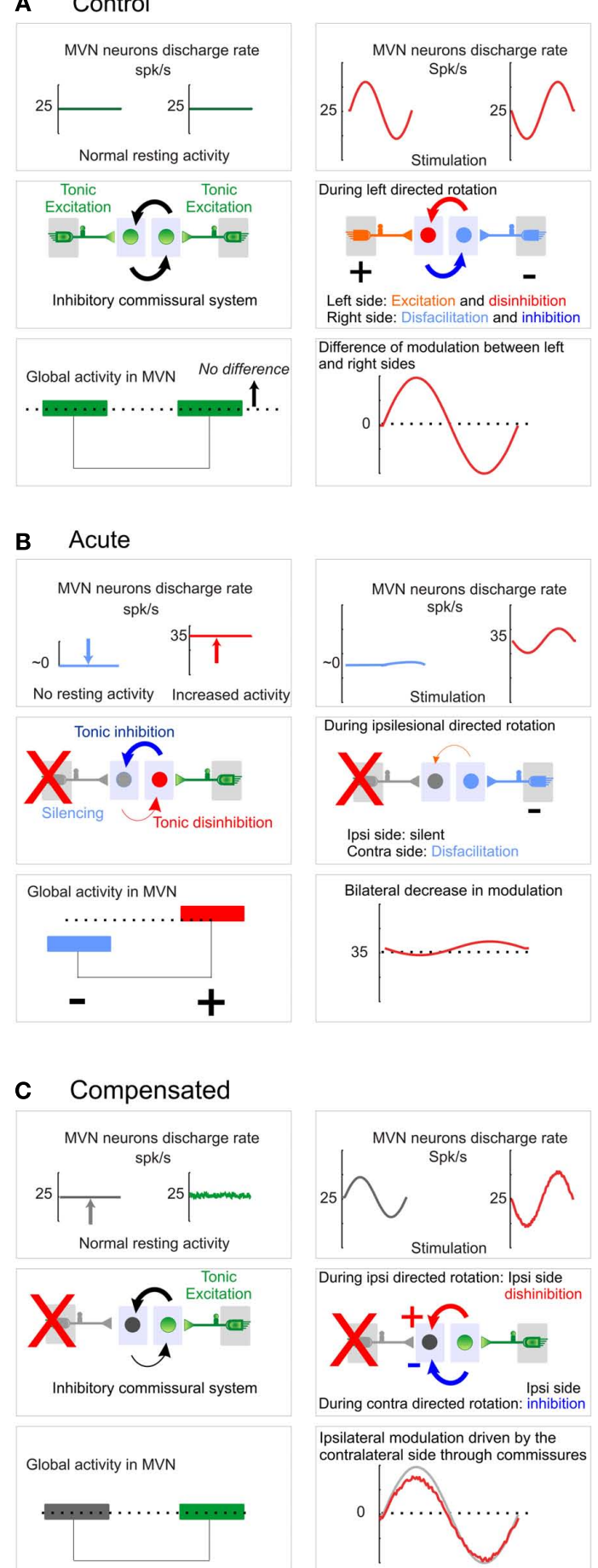

During left directed rotation

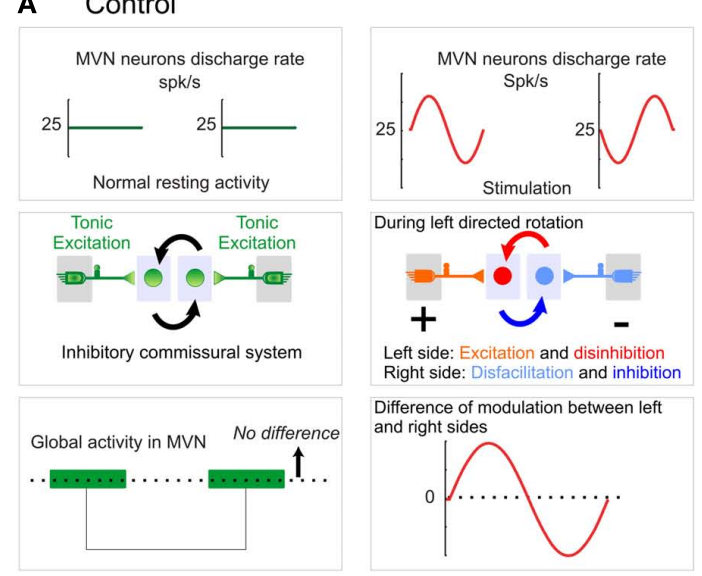

Left side: Excitation and disinhibition

Difference of modulation between left and right sides

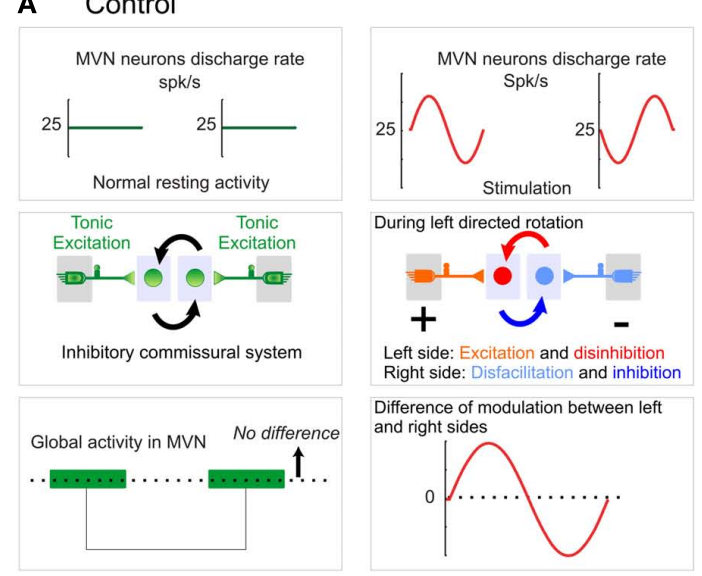

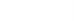

\section{A Control}

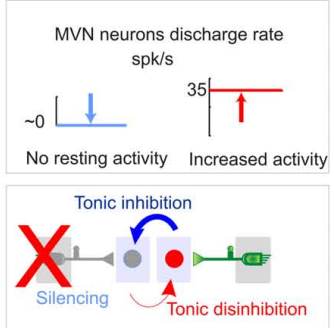

FIGURE 3 | Continued

activity at rest and a differential perception of the movement: movements elicit both ipsilateral excitation and contralateral disfacilitation $\left(1^{\circ} \mathrm{VN}\right.$ to $2^{\circ}$ VN) which are amplified by the commissural inhibition (increased inhibition from the ipsilateral side to the contralateral side and conversely disinhibition from contralateral to ipsilateral). (B) Acute. Schematics represent the activity typically recorded $24 \mathrm{~h}$ after the lesion. The ipsilesional neurons lose their excitatory drive and are therefore silenced by the commissural inhibition. In turn, the contralesional side is disinhibited, which causes a strong imbalance in the absence of movements. During movements, the balanced activity used as a carrier signal cannot be modulated anymore by the reciprocal connections of both vestibular nuclei. Thus only movements toward the contralesional side can be detected, however with a decreased sensitivity. (C) Compensated. Schematics represent the activity typically recorded 1 month after the lesion and is "compensated" from a static point of view (see Behavioral Correlates of Vestibular Compensation). In the absence of movement, the balanced activity is restored between both sides. When a rotation is applied, this basal activity can be modulated by the sensory inputs from the contralesional side through the inhibitory commissural system. The system has evolved from an initial symmetrical push-pull organization to a new regime where the ipsilesional side restores a tonic discharge which is more or less inhibited by the contralesional side during respectively contra and ipsilesional movements: the ipsilateral

"carrier" activity is modulated by the contralateral phasic signals, at the expenses of the signal-to-noise ratio.

1997). The $2^{\circ} \mathrm{VN}$ silenced by the UL become active again merely $12 \mathrm{~h}$ after the lesion, and recover in vivo a normal discharge rate 1 week after the lesion. In parallel, postural symptoms already improve $90 \mathrm{~min}$ after the surgery and the nystagmus is reduced during the first $12 \mathrm{~h}$, in the absence of recovery in $2^{\circ} \mathrm{VN}$ resting rate. The nature of vestibular compensation neural correlates as well as the time course of their onset was also investigated in vitro, including with the Guinea pig whole-brain preparation (Vibert et al., 1999a). This ex vivo technique allows the electrophysiological characterization of the vestibular-related networks, with the caveat that it constitutes an acute bilaterally deprived preparation. When such preparation is recorded after the animal has undergone UL and compensation, results comparable to Bechterew's phenomenon are found, yet at the cellular level: the longer the time between the initial lesion and the experiment, the more asymmetrical the electrophysiological properties become between the two sides of the preparation. Moreover, the persistence of cellular modifications in the isolated whole-brain indicates that from the third day on, most of cellular correlates are likely to be independent of external factors such as other synaptic signals and/or neuromodulation. Based on these experiments, a so-called "top-down hypothesis" was proposed (Vibert et al., 1999b) that we revisit in the following paragraphs.

Based on this evidence, it is proposed that the mechanisms of compensation would go from the global to local (Figure 4). Vestibular compensation would initially rely on behavioral substitutions, i.e., external cues given by other, intact sensory systems. Then, an internal reorganization of the vestibular-related networks would become noticeable (i.e., coarsely, changes in neuromodulation and synaptic weights). After the first week, more and more changes would start to appear in the intrinsic properties of $2^{\circ} \mathrm{VN}$. Within this framework, dynamic compensation improves with time as deeper modifications are engraved within the finer parts of the vestibular-related networks. Importantly, there is no causal
FIGURE 3 | Vestibular nuclei activity at control, acute, or compensated stage. For (A-C), Left panels: resting condition; right panels: during sinusoidal movement. Top, middle, and bottom panels represent respectively the average discharge in left and right vestibular nuclei, the excitatory/inhibitory relations between $1^{\circ}$ and $2^{\circ} \mathrm{VN}$ (MVN) as well as the influence of commissural inhibition, and finally the resting balanced activity (left) and global modulation of activity (right) within vestibular nuclei. (A) Control. Vestibular nuclei work as a symmetrical, push-pull system, with a balanced 


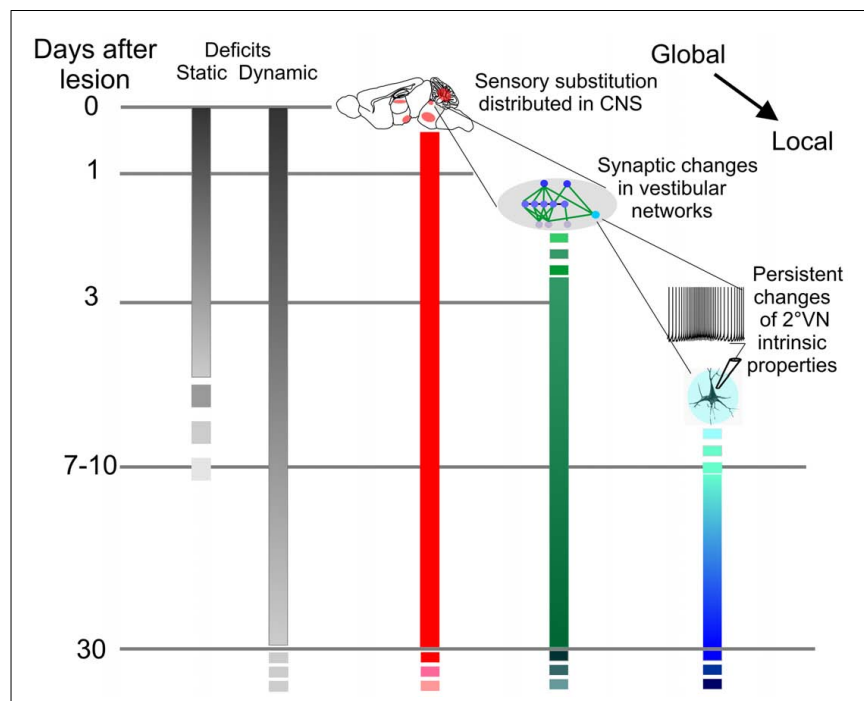

FIGURE 4 | Dynamic of vestibular compensation and neural correlates. Compensation of static and dynamic deficits is presented in gray scales. Static deficits get compensated in about a week while dynamic compensation follows a slower time course over several months or years. Neural correlates associated to sensory substitution (red) depend on structures distributed throughout the entire central nervous system (CNS) and encompass all kinds of structural plasticities. Synaptic (green) and intrinsic (blue) scales represent the neural correlates at the level of the vestibular nuclei based on in vitro works. With time, deeper modifications are engraved within the finer parts of the vestibular-related networks. Importantly, there is no causal relationship postulated between the parallel processes. Instead, the hypothesis is to be understood as a "basic reaction pattern" which includes all the cellular events initially triggered by the lesion.

relationship postulated between the different steps, i.e., the early sensory substitution does not mechanistically trigger the synaptic changes which in turn are not directly responsible for the apparently subsequent intrinsic properties modifications. Instead, the hypothesis is to be understood as a "basic reaction pattern," which includes all the cellular events triggered by the lesion (Dieringer, 1995, 2003; Kaas, 2000; Straka et al., 2005). Each form of plasticity follows its own time course: the slowest ones have the same starting point but take more time to become detectable in vitro.

We now detail the experimental evidence in favor of the implication of changes in intrinsic properties during vestibular compensation. Please note that many studies have demonstrated that major synaptic changes occur early after the lesion (Vibert et al., 2000; Yamanaka et al., 2000; Johnston et al., 2001). Because these mechanisms have received lot of attention, interested readers can find more detailed information in the following papers: Kitahara et al. (1998), Grassi and Pettorossi (2001), Gittis and du Lac (2006), Bergquist et al. (2008), Shao et al. (2012).

\section{VESTIBULAR COMPENSATION INDUCES SLOW AND LONG-LASTING MODIFICATIONS IN CENTRAL VESTIBULAR NEURONS INTRINSIC PROPERTIES \\ EARLY ALTERATIONS IN $2^{\circ}$ VN INTRINSIC PROPERTIES ARE TRANSITORY}

Changes of $2^{\circ} \mathrm{VN}$ intrinsic properties are noticed in early extracellular recordings in Guinea pig or Rat brainstem slices. In Rat brainstem slices, the spontaneous activity of $2^{\circ} \mathrm{VN}$ located on the ipsilesional side transitorily increases between the 4 th and 24th hour following the surgical deafferentation (Cameron and Dutia, 1997). This increase in spontaneous activity is however transitory and concerns the rostral, but not the caudal, part of the medial vestibular nuclei. Indeed, from the second day onward, increase in the spontaneous activity critically depends on synaptic inputs as demonstrated using cocktails of antagonists (Guilding and Dutia, 2005). Interestingly, intracellular recordings suggest that the ipsilesional type B neurons are preferentially affected, while type A neurons appear left untouched until the 7-11th day after the lesion (Him and Dutia, 2001). In Guinea pigs as in Rats, the few observed changes 7 days after the UL are restricted to type $B$ neurons, yet with little persistence of the changes in intrinsic membrane properties of ipsilesional $2^{\circ} \mathrm{VN}$ (Ris et al., 2002).

Furthermore, when the recording takes place in vitro after 6 8 weeks of compensation, a strong imbalance is measured between the increased resting discharge of ipsilesional $2^{\circ} \mathrm{VN}$ and the contralesional $2^{\circ} \mathrm{VN}$, more often silent and with an overall lower resting discharge (Darlington et al., 1989; Vibert et al., 1999b). Longer-term imbalance in spontaneous activity suggests that additional modifications with slow dynamics might occur after the end of the 15th postlesional day. Thus, membrane properties are not permanently altered right after the lesion. The transitory intrinsic hyperactivity may be related to $\mathrm{Ca}^{2+}$ waveshock or Firing Rate Potentiation mechanisms (Nelson et al., 2003) and occur between the 4 th and the 24th hour post-lesion. Changes in spontaneous activity then depend on synaptic inputs during the following days, while modifications of membrane properties of type $B$, but not yet of type A, neurons begin to persist on slices. To confirm the existence of modifications after longer compensation duration, we recorded the intrinsic properties of medial $2^{\circ} \mathrm{VN}$ on slices taken from animals 1 month after UL and measured their static and dynamic intrinsic properties following injections of ramps, sine waves and steps of currents (Beraneck et al., 2003, 2004).

\section{LONG-TERM CHANGES IN $2^{\circ}$ VN INTRINSIC PROPERTIES}

Modifications of the membrane properties are qualitatively and quantitatively more extensive after 1 month of compensation than after 7-10 days. For instance, depolarization of the resting membrane potential and increase in the input resistance, reported only for type B neurons by Him and Dutia (2001), are larger for type B neurons and also found in type A neurons. The ongoing compensation leads to a depolarization of both the resting membrane potential and firing threshold of all MVN neurons of $\sim 7 \mathrm{mV}$ (Beraneck et al., 2003): the initial restoration of spontaneous activity promoted by synaptic reorganization after a week is engraved into the membrane properties after a month. Non-linear properties, such as the overshoot of the firing rate in response to current-ramps, which were restricted to type B neurons, appear in type A neurons after 1 month together with an increased excitability. Overall, the early trends in intrinsic properties modifications are strengthened in time during compensation and concern an increasing proportion of the MVN neurons. In addition, several new changes are found, such as an increase in the afterhyperpolarization and discharge regularity of type $\mathrm{B}$ neurons of the ipsilesional nuclei, modifications that should stabilize the restored 
activity. Overall, the membrane properties recorded on the ipsilesional side are dominated by type A-like tonic properties, while the characteristics of type B neurons seem more affected by the loss of vestibular inputs.

After UL, detection of head movements and restoration of vestibular-related reflexes critically depend on the performance of the contralesional side. However, little is known about the evolution of the electrophysiological properties of contralesional $2^{\circ} \mathrm{VN}$ following UL (Ris and Godaux, 1998; Beraneck et al., 2004). As previously reported (Darlington et al., 1989; Vibert et al., 1999b), silent neurons are twice as frequent as in controls. Strikingly, the proportion of type B neurons also increases while the amplitude of their AHP decreases, making the ipsi- and contralesional changes opposite in many ways. Hence, on top of being less numerous, remaining type A neurons are particularly affected on the contralesional side. For instance, the sensitivity of the discharge to current injection is increased only for contralesional type A neurons and ipsilesional type $\mathrm{B}$ neurons. Overall, the contralesional side is found to be dominated by the phasic, type B-like membrane properties.

\section{INTERPRETATIONS AND HYPOTHESES ON THE LONG-TERM INTRINSIC MODIFICATIONS}

Recently, it was proposed that vestibular signal processing would rely on separate sets of neuronal filters (Beraneck and Straka, 2011) creating complementary tonic and phasic frequency-tuned channels (Straka et al., 2009). To achieve it, synaptic properties of the primary afferent have to match those of the neurons (Rössert and Straka, 2011; Rössert et al., 2011). Whether the nature and dynamics of the synaptic inputs are responsible for shaping the neuronal filtering properties of this co-adaptation is not known yet.

Following UL, the cellular mechanisms that sustain changes on each side are not equivalent (Kitahara et al., 1998; Beraneck et al., 2008). Because the $2^{\circ} \mathrm{VN}$ contralesional neurons are neither silenced nor functionally deafferented, their extensive modifications must reflect long-term adaptations to the reshaped activity both within and out of the vestibular nuclei (Figure 5). Interestingly, the dynamics of the vestibular regular and irregular afferents were similar between labyrinthectomized and control monkeys (Sadeghi et al., 2007b). However, the proportion of the phasic irregular afferents increases while the proportion of the tonic,

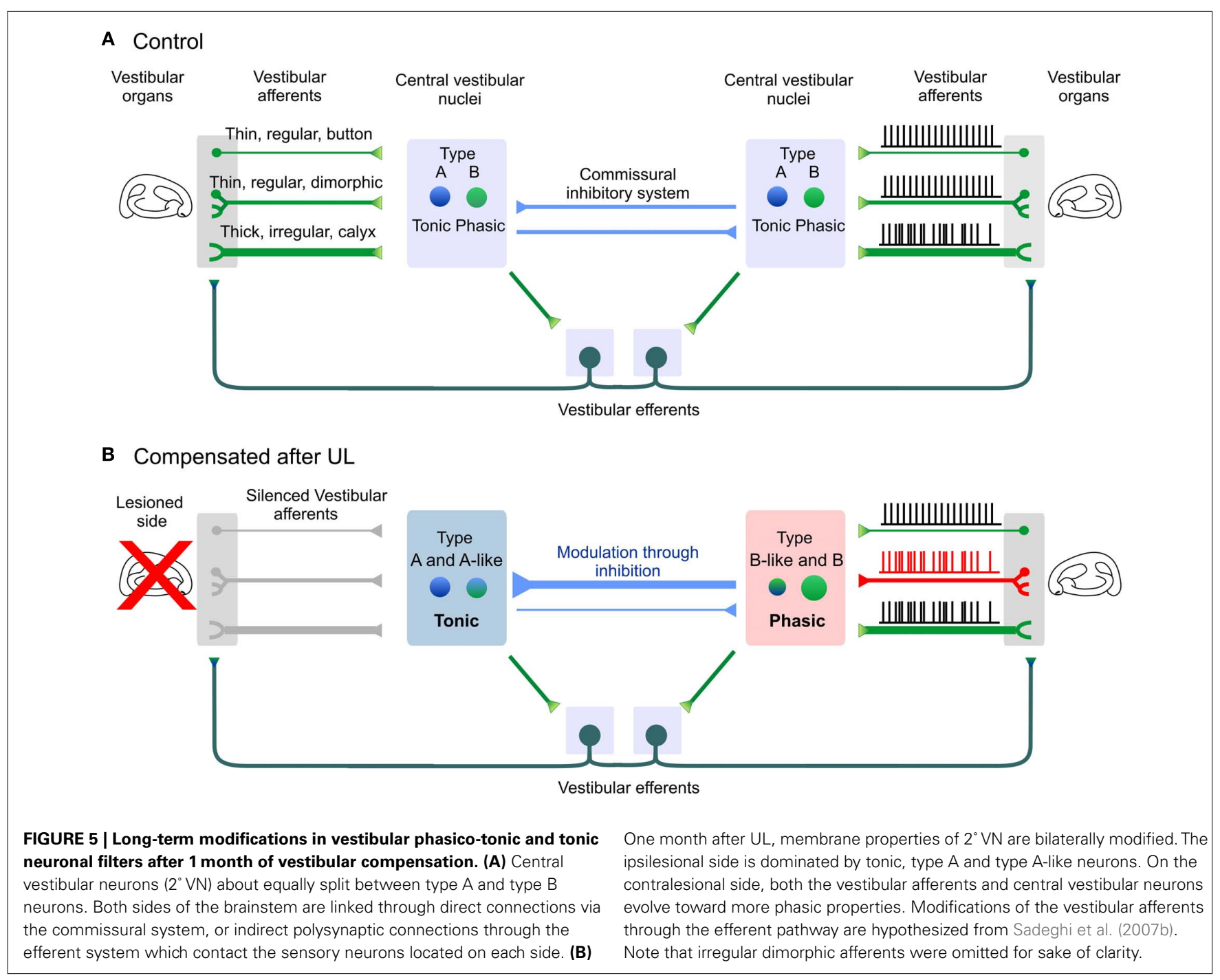


regular afferents decreases (Sadeghi et al., 2007b). This shift could be explained by the role of the efferent system, which would have modified the responses of the regular dimorphic afferents (Sadeghi et al., 2007b; Cullen et al., 2009). Remarkably, this shift in the proportion of the two types of afferents mimics the changes in the intrinsic properties of contralesional $2^{\circ} \mathrm{VN}$ (qualitative and quantitative increase of type B phasic properties; cf. supra). Thus, following UL, peripheral and central neuronal elements of the contralesional side evolve together toward more phasic properties. Notably, models of the VOR compensation (Lasker et al., 2000) had predicted changes in the properties of phasic central neurons (i.e., type B-like) and an increase in the gain of the phasic peripheral pathway (i.e., irregular afferents).

Modifications of the ipsilesional neurons can largely be interpreted within the framework of functional deafferentation or of a persistent deprivation of activity which triggers homeostaticlike plasticity (Turrigiano, 2011). The depolarization of $2^{\circ} \mathrm{VN}$ and the alterations observed in the electrophysiological signatures of type $\mathrm{B}$ neurons resemble the properties of $2^{\circ} \mathrm{VN}$ recorded during early development (Dutia et al., 1995; Dutia and Johnston, 1998), or in juvenile mutant mice suffering from congenital absence of vestibular inputs (Eugène et al., 2007). One hypothesis to explain the particular alterations of type B ipsilesional neurons is that their electrophysiological characteristics would critically depend on the vestibular glutamatergic neurotransmission. Deprived from their main excitatory input, type B neurons' intrinsic properties would "dedifferentiate" and express more A-like properties. Another nonexclusive option would be that the type B electrophysiological signature would be reshaped by the changes in the glycinergic neurotransmission. Indeed, it was recently shown in mutant mice suffering from deficiencies in the glycine receptor that a subset of type B neurons was preferentially affected (Camp et al., 2010). Finally, a "basic reaction pattern" was proposed, which would substitute the deprived inputs with other non-preferred inputs (Goto et al., 2001; Dieringer, 2003; Rohregger and Dieringer, 2003). In this hypothesis, it is conceivable that type B neurons' intrinsic properties would slowly be reshaped by newly recruited or reinforced inputs and more particularly from the commissural inputs (Camp et al., 2010). Following UL, the commissural inhibitory system becomes essential both to restore the balance during initial compensation (Vibert et al., 2000; Yamanaka et al., 2000; Bergquist et al., 2008; Olabi et al., 2009) and to allow modulation of activity by the remaining vestibular inputs. Because type A neurons are thought to be GABAergic (Takazawa, 2004; Bagnall et al., 2007) and to receive GABA inputs (Camp et al., 2006), their role is probably essential in the long-term functioning of the commissural inhibition. Hence, the number of GAD67 positive neurons triples in the ipsilesional nuclei during the first month of compensation (Dutheil et al., 2011). In addition, the level of GABA released in the contralesional, but not the ipsilesional, nuclei remains decreased after 4 days of compensation even though the initial static symptoms have abated (Bergquist et al., 2008). This persistent imbalance, together with the reinforcement of the type A-like properties on the ipsilesional side, could reflect an internal reorganization of the commissural system essential in the modulation of the ipsilesional activity by the remaining vestibular inputs.
In conclusion, the membrane properties are bilaterally affected 1 month after the lesion. Compared to the modifications observed after 7-10th days, the modifications are more comprehensive, which demonstrates that persistent modifications of the intrinsic properties occur with a slower time course, dissociated from the recovery of the static symptoms, yet matching the steady reduction of the dynamic deficits. We propose that long-term evolution of the ipsilesional $2^{\circ} \mathrm{VN}$ toward type A-like tonic membrane properties helps maintaining the global ipsilesional activity (Beraneck et al., 2003) and reflects the increased influence of the commissural system in modulation of $2^{\circ} \mathrm{VN}$ (Figure 3C, "compensated" state). On the other hand, the intrinsic properties encountered on the contralesional afferents and $2^{\circ} \mathrm{VN}$ are dominated by the type B-like phasic membrane properties (Beraneck et al., 2004) which will favor the vestibular event detection of movements at higher frequencies (Sadeghi et al., 2007a; Beraneck and Straka, 2011).

\section{PERSPECTIVES FOR FUTURE RESEARCH DYNAMICS OF SYNAPTIC AND INTRINSIC CHANGES IN VESTIBULAR COMPENSATION: CASCADES OF PLASTICITY IN THE VESTIBULAR SYSTEM?}

Following UL, the functional deafferentation, stress response, and the mismatch between the vestibular information and the intact sensory modalities (e.g., proprioception, vision) trigger many cellular events with different dynamics. Drastic modifications of the intrinsic properties are a long, continuous phenomenon. One hypothesis to explain such dynamics would be that intrinsic properties modification is not a consequence of the initial deafferentation but rather reflects the establishment of a new equilibrium within vestibular networks. Such hypothesis postulates that the neuronal filters constituted by matching synaptic and intrinsic membrane properties are also continuously co-regulated, including during postlesional plasticity. Cascade models of synaptic plasticity have shown that long-term retention takes several stages with dynamics distributed over a wide range of timescale (Fusi et al., 2005). Such models clearly demonstrate that the most persistent modifications occur with the slowest dynamics, which strengthen both the learning and retention capacities within the network.

\section{A ROLE FOR THE NEUROMODULATION IN THE LONG-TERM ALTERATION OF $2^{\circ}$ VN INTRINSIC PROPERTIES?}

Here, we have emphasized the dual dynamics of rapid changes in excitability by neuromodulators and the slower dynamic of persistent intrinsic plasticity. Neuromodulation, however, has longterm influence on the intrinsic properties of particular neurons. Recently, it was demonstrated in vitro that neuromodulatory inputs might regulate the correlated expression of specific subset of ion channels in a cell-specific manner (Temporal et al., 2012). Similar regulation in the vestibular system is likely to occur during vestibular compensation. Of particular interests are the neuromodulators that appear to have differential influence on type A and type B neurons, e.g., the cholinergic system.

Other neuromodulators regulate glutamatergic and GABAergic systems and could therefore influence the long-term evolution of $2^{\circ} \mathrm{VN}$ intrinsic properties. For example, 17 beta-estradiol, an estrogenic steroid modulates glutamatergic responsiveness of type 
B neurons and decreases the excitability of both type A and type B neurons (Grassi et al., 2010). Other stress steroids or NAd are also involved in the mechanisms of the compensation themselves (Cameron and Dutia, 1999; Guilding et al., 2004; Grassi et al., 2007). Histamine improves vestibular compensation as well (Tighilet et al., 2007) and modifies the GABA release for up to 3 weeks post-lesion (Bergquist et al., 2006). Histaminergic control of GABA release also implicates glycine-mediated modulation and relies on different mechanisms during early or late compensation (Bergquist and Dutia, 2006; Bergquist et al., 2006). More work is needed to understand the long-term effects of neuromodulators on the intrinsic properties of $2^{\circ} \mathrm{VN}$.

\section{CHANGES IN INTRINSIC PROPERTIES FOLLOWING ADAPTATIONS?}

This review has pitted the fast neuromodulation with nonpersistent changes against the long-lasting changes following lesion. But what happens when the changes have an intermediate time course, i.e., slower than the transitions between the different stages of sleep but not as definitive as a lesion?

Vestibular adaptation is a perfect paradigm to explore such timescales. Indeed, the recalibration of the VOR depends on the mismatch of visual and vestibular inputs and is mediated by the vestibulo-cerebellum. While the initial learning is stored within the cerebellum, long-term adaptation protocol (Shutoh et al., 2006), and occlusion experiments (Okamoto et al., 2011) have demonstrated that long-term, persistent changes probably involve a transfer of memory from the cerebellum to the vestibular nuclei. While part of the transferred memory could be engraved at the level of the synapse between the vestibular afferents and $2^{\circ} \mathrm{VN}$ (Menzies et al., 2010), another complementary possibility would be that the intrinsic properties of floccular target neurons (Shin et al., 2011) would carry part of this information.

The functioning of the vestibular system critically depends on the range of head movements produced during locomotion (Straka et al., 2004; Beraneck and Straka, 2011). The synaptic and intrinsic properties of $2^{\circ} \mathrm{VN}$ are co-adapted and match these behavioral requirements. Long-term alteration of the vestibular inputs and changes in the dynamics of head movements are encountered during space journey or experimentally when animals are kept in centrifuges. Theoretically, long-term adaptations to new gravity-related signals and/or to changes in the dynamics of head movements in altered-gravity environments could require modifications of intrinsic properties. Future experiments on longterm centrifuged rodents would allow this particular hypothesis to be tested.

\section{CONCLUDING REMARKS}

\section{FRAMING INTRINSIC MEMBRANE PLASTICITY IN OTHER SYSTEMS}

Vestibular compensation represents a unique model to investigate how the brain reacts when major deafferentations occur following pathological situations such as strokes or surgeries.

\section{REFERENCES}

Angelaki, D. E., and Cullen, K. E. (2008). Vestibular system: the many facets of a multimodal sense. Annu. Rev. Neurosci. 31, 125-150.
Argence, M., Saez, I., Sassu, R., Vassias, I., Vidal, P. P., and de Waele, C. (2006). Modulation of inhibitory and excitatory synaptic transmission in rat inferior colliculus after unilateral cochleectomy: an in situ and

Modifications in intrinsic properties can lead to long-lasting alterations of the spontaneous firing or of the neuronal excitability, and we have shown that heterogeneous changes occur within a particular nucleus. Functional deafferentation can lead to dramatic maladaptive phenomena such as phantom perceptions. The auditory phantom pain known as tinnitus is of particular interest because of the high resemblance of the vestibular system to the auditory system. Tinnitus occurs following a partial peripheral deafferentation and is also related to an increase in spontaneous activity and changes in inhibitory pathways (Argence et al., 2006; Wang et al., 2011). Following spinal cord injury, changes in the proportions of cells, increases in spontaneous activity, and many abnormal intrinsic properties are seen in dorsal horn and thalamic neurons. Interestingly, the prevalence of chronic pain often increases with time after injury (Waxman and Hains, 2006), which again suggests that the "local" changes in intrinsic properties follows a very slow dynamic. While all neurons are not equal in the face of pathological situations, understanding the common ground, and differences, will provide options for future treatments and rehabilitation of normal perceptions following massive deafferentations.

\section{BRIDGING THE GAP BETWEEN IN VITRO AND IN VIVO EXPERIMENTS}

A lot of work is put into identifying the neural substrates of the vestibular-related functions and the changes they undergo during vestibular compensation or other forms of plasticity. Recording in acute brainstem slices is one of the best ways to work in a stable, controlled environment to investigate the functional properties at the cellular level. However, unless the effects of the neuromodulators are the focus of the study, the typical medium bathing the slice is totally depleted of the monoamines and ACh. Therefore, the typical intrinsic properties of neurons recorded in a slice are, by definition, depleted from their most labile, nonetheless powerful, neuromodulation. As we have seen, a typical vestibular function such as the VOR is mainly nonfunctional during the stages of sleep where these neuromodulators are at a low concentration. This can explain the difficulty in bridging the gap between in vivo experiments and the in vitro slice recordings, and it illustrates the distance we, neurophysiologists, have to travel from our benches to meet clinicians at the bedside.

\section{ACKNOWLEDGMENTS}

This work was supported by the Centre National d'Etudes Spatiales, the Agence Nationale de la Recherche (program ANR-09BLAN-0148), CNRS PEPS, and Neuro-IC programs. E. Idoux received fellowship from the CNES. The authors would like to thank Ms Ashton, Dr. Sadeghi, and Prof. Eugène for critically reading the manuscript, the reviewers for useful comments, and the editors for their invitation.

immunofluorescence study. Neuroscience 141, 1193-1207.

Babalian, A., Vibert, N., Assie, G., Serafin, M., Mühlethaler, M., and Vidal, P. P. (1997). Central vestibular networks in the guinea-pig: functional characterization in the isolated whole brain in vitro. Neuroscience 81, 405-426.

Bagnall, M. W., Stevens, R. J., and du Lac, S. (2007). Transgenic mouse lines subdivide medial vestibular nucleus 
neurons into discrete, neurochemically distinct populations. J. Neurosci. 27, 2318-2330.

Balaban, C. D., Jacob, R. G., and Furman, J. M. (2011). Neurologic bases for comorbidity of balance disorders, anxiety disorders and migraine: neurotherapeutic implications. Expert Rev. Neurother. 11, 379-394.

Bechterew, W. (1883). Ergebnisse der Durchschneidung des N. acusticus, nebst Erörterung der Bedeutung der semicirculären Canäle für das Körpergleichgewicht. Pflugers Arch. Gesamte Physiol. Menschen Tiere 30, 312-347.

Beraneck, M., Hachemaoui, M., Idoux, E., Ris, L., Uno, A., Godaux, E., Vidal, P.-P., Moore, L. E., and Vibert, N. (2003). Long-term plasticity of ipsilesional medial vestibular nucleus neurons after unilateral labyrinthectomy. J. Neurophysiol. 90, 184-203.

Beraneck, M., Idoux, E., Uno, A., Vidal, P.-P., Moore, L. E., and Vibert, N. (2004). Unilateral labyrinthectomy modifies the membrane properties of contralesional vestibular neurons. J. Neurophysiol. 92, 1668-1684.

Beraneck, M., McKee, J. L., Aleisa, M., and Cullen, K. E. (2008). Asymmetric recovery in cerebellardeficient mice following unilateral labyrinthectomy. J. Neurophysiol. 100, 945-958.

Beraneck, M., Pfanzelt, S., Vassias, I., Rohregger, M., Vibert, N., Vidal, P.-P., Moore, L. E., and Straka, H. (2007). Differential intrinsic response dynamics determine synaptic signal processing in frog vestibular neurons. J. Neurosci. 27, 4283-4296.

Beraneck, M., and Straka, H. (2011). Vestibular signal processing by separate sets of neuronal filters. J. Vestib. Res. 21, 5-19.

Bergquist, F., and Dutia, M. B. (2006). Central histaminergic modulation of vestibular function - a review. Sheng Li Xue Bao 58, 293-304.

Bergquist, F., Ludwig, M., and Dutia, M. B. (2008). Role of the commissural inhibitory system in vestibular compensation in the rat. J. Physiol. (Lond.) 586, 4441-4452.

Bergquist, F., Ruthven, A., Ludwig, M., and Dutia, M. B. (2006). Histaminergic and glycinergic modulation of GABA release in the vestibular nuclei of normal and labyrinthectomised rats. J. Physiol. (Lond.) 577, 857-868.

Biesdorf, S., Malinvaud, D., Reichenberger, I., Pfanzelt, S., and Straka, H. (2008). Differential inhibitory control of semicircular canal nerve afferent-evoked inputs in second-order vestibular neurons by glycinergic and GABAergic circuits. J. Neurophysiol. 99, 1758-1769.

Bizzi, E., Pompeiano, O., and Somogyi, I. (1964). Vestibular nuclei: activity of single neurons during natural sleep and wakefulness. Science 145, 414.

Cameron, S. A., and Dutia, M. B. (1997). Cellular basis of vestibular compensation: changes in intrinsic excitability of MVN neurones. Neuroreport 8 , 2595-2599.

Cameron, S. A., and Dutia, M. B. (1999). Lesion-induced plasticity in rat vestibular nucleus neurones dependent on glucocorticoid receptor activation. J. Physiol. (Lond.) 518(Pt 1), 151-158.

Camp, A. J., Callister, R. J., and Brichta, A. M. (2006). Inhibitory synaptic transmission differs in mouse type $\mathrm{A}$ and $\mathrm{B}$ medial vestibular nucleus neurons in vitro. J. Neurophysiol. 95, 3208.

Camp, A. J., Lim, R., Anderson, W. B., Schofield, P. R., Callister, R. J., and Brichta, A. M. (2010). Attenuated glycine receptor function reduces excitability of mouse medial vestibular nucleus neurons. Neuroscience 170, 348-360.

Chokroverty, S. (2010). Overview of sleep and sleep disorders. Indian J. Med. Res. 131, 126-140.

Cullen, K. E., Minor, L. B., Beraneck, M., and Sadeghi, S. G. (2009). Neural substrates underlying vestibular compensation: contribution of peripheral versus central processing. J. Vestib. Res. 19, 171-182.

Curthoys, I. S. (2000). Vestibular compensation and substitution. Curr. Opin. Neurol. 13, 27-30.

Darlington, C. L., Dutia, M. B., and Smith, P. F. (2002). The contribution of the intrinsic excitability of vestibular nucleus neurons to recovery from vestibular damage. Eur. J. Neurosci. 15, 1719-1727.

Darlington, C. L., Gallagher, J. P., and Smith, P. F. (1995). In vitro electrophysiological studies of the vestibular nucleus complex. Prog. Neurobiol. 45, 335-346.

Darlington, C. L., and Smith, P. F. (2000). Molecular mechanisms of recovery from vestibular damage in mammals: recent advances. Prog. Neurobiol. 62, 313-325.

Darlington, C. L., Smith, P. F., and Hubbard, J. I. (1989). Neuronal activity in the guinea pig medial vestibular nucleus in vitro following chronic unilateral labyrinthectomy. Neurosci. Lett. 105, 143-148. de Waele, C., Mühlethaler, M., and Vidal, P. P. (1995). Neurochemistry of the central vestibular pathways. Brain Res. Brain Res. Rev. 20, 24-46.

Dieringer, N. (1995). "Vestibular compensation": neural plasticity and its relations to functional recovery after labyrinthine lesions in frogs and other vertebrates. Prog. Neurobiol. 46, 97-129.

Dieringer, N. (2003). Activity-related postlesional vestibular reorganization. Ann. N. Y. Acad. Sci. 1004, 50-60.

du Lac, S., and Lisberger, S. G. (1995). Membrane and firing properties of avian medial vestibular nucleus neurons in vitro. J. Comp. Physiol. A 176, 641-651.

Dutheil, S., Lacour, M., and Tighilet, B. (2011). Neurogenic potential of the vestibular nuclei and behavioural recovery time course in the adult cat are governed by the nature of the vestibular damage. PLoS ONE 6, e22262. doi:10.1371/journal.pone. 0022262

Dutia, M. B., and Johnston, A. R. (1998). Development of action potentials and apamin-sensitive after-potentials in mouse vestibular nucleus neurones. Exp. Brain Res. 118, 148-154.

Dutia, M. B., Lotto, R. B., and Johnston, A. R. (1995). Post-natal development of tonic activity and membrane excitability in mouse medial vestibular nucleus neurones. Acta Otolaryngol. Suppl. 520(Pt 1), 101-104.

Eugène, D., Deforges, S., Guimont, F., Idoux, E., Vidal, P.-P., Moore, L. E., and Vibert, N. (2007). Developmental regulation of the membrane properties of central vestibular neurons by sensory vestibular information in the mouse. J. Physiol. (Lond.) 583, 923-943.

Eugène, D., Idoux, E., Beraneck, M., Moore, L. E., and Vidal, P.-P. (2011). Intrinsic membrane properties of central vestibular neurons in rodents. Exp. Brain Res. 210, 423-436.

Fusi, S., Drew, P. J., and Abbott, L. F. (2005). Cascade models of synaptically stored memories. Neuron 45, 599-611.

Gallagher, J. P., Lewis, M. R., and Gallagher, P. S. (1985). An electrophysiological investigation of the rat medial vestibular nucleus in vitro. Prog. Clin. Biol. Res. 176, 293-304.

Gilchrist, D. P., Curthoys, I. S., Cartwright, A. D., Burgess, A. M., Topple, A. N., and Halmagyi, M. (1998). High acceleration impulsive rotations reveal severe long-term deficits of the horizontal vestibuloocular reflex in the guinea pig. Exp. Brain Res. 123, 242-254.

Gittis, A. H., and du Lac, S. (2006). Intrinsic and synaptic plasticity in the vestibular system. Curr. Opin. Neurobiol. 16, 385-390.

Goto, F., Straka, H., and Dieringer, N. (2001). Postlesional vestibular reorganization in frogs: evidence for a basic reaction pattern after nerve injury. J. Neurophysiol. 85, 2643-2646.

Gottesman-Davis, A., and Peusner, K. D. (2010). Identification of vestibuloocular projection neurons in the developing chicken medial vestibular nucleus. J. Neurosci. Res. 88, 290-303.

Gottesman-Davis, A., Shao, M., Hirsch, J. C., and Peusner, K. D. (2011). Electrophysiological properties of morphologically-identified medial vestibular nucleus neurons projecting to the abducens nucleus in the chick embryo. Neuroscience 172 , 494-509.

Grassi, S., Frondaroli, A., Dieni, C., Dutia, M. B., and Pettorossi, V. E. (2007). Neurosteroid modulation of neuronal excitability and synaptic transmission in the rat medial vestibular nuclei. Eur. J. Neurosci. 26, 23-32.

Grassi, S., Frondaroli, A., Dieni, C., Scarduzio, M., and Pettorossi, V. E. (2009). Long-term potentiation in the rat medial vestibular nuclei depends on locally synthesized 17beta-estradiol. J. Neurosci. 29, 10779-10783.

Grassi, S., Frondaroli, A., Scarduzio, M., Dutia, M. B., Dieni, C., and Pettorossi, V. E. (2010). Effects of 17beta-estradiol on glutamate synaptic transmission and neuronal excitability in the rat medial vestibular nuclei. Neuroscience 165 , 1100-1114.

Grassi, S., and Pettorossi, V. E. (2001). Synaptic plasticity in the medial vestibular nuclei: role of glutamate receptors and retrograde messengers in rat brainstem slices. Prog. Neurobiol. 64, 527-553.

Guilding, C., and Dutia, M. B. (2005). Early and late changes in vestibular neuronal excitability after deafferentation. Neuroreport 16, 1415-1418.

Guilding, C., Seckl, J. R., and Dutia, M. B. (2004). 11Beta-hydroxysteroid dehydrogenase type 1 activity in medial vestibular nucleus and cerebellum after unilateral vestibular deafferentation in the rat. Stress 7 , 127-130. 
Halberstadt, A. L., and Balaban, C. D. (2003). Organization of projections from the raphe nuclei to the vestibular nuclei in rats. Neuroscience 120, 573-594.

Him, A., and Dutia, M. B. (2001). Intrinsic excitability changes in vestibular nucleus neurons after unilateral deafferentation. Brain Res. 908, 58-66.

Hirata, Y., Nishiyama, J., and Kinoshita, S. (2009). Detection and prediction of drowsiness by reflexive eye movements. Conf. Proc. IEEE Eng. Med. Biol. Soc. 2009, 4015-4018.

Horowitz, S. S., Blanchard, J., and Morin, L. P. (2005). Medial vestibular connections with the hypocretin (orexin) system. J. Comp. Neurol. $487,127-146$.

Idoux, E., Eugène, D., Chambaz, A., Magnani, C., White, J. A., and Moore, L. E. (2008). Control of neuronal persistent activity by voltagedependent dendritic properties. $J$. Neurophysiol. 100, 1278-1286.

Johnston, A. R., and Dutia, M. B. (1996). Postnatal development of spontaneous tonic activity in mouse medial vestibular nucleus neurones. $\mathrm{Neu}$ rosci. Lett. 219, 17-20.

Johnston, A. R., Him, A., and Dutia, M. B. (2001). Differential regulation of $\operatorname{GABA}(\mathrm{A})$ and $\mathrm{GABA}(\mathrm{B})$ receptors during vestibular compensation. Neuroreport 12, 597-600.

Johnston, A. R., MacLeod, N. K., and Dutia, M. B. (1994). Ionic conductances contributing to spike repolarization and after-potentials in rat medial vestibular nucleus neurones. J. Physiol. (Lond.) 481(Pt 1), 61-77.

Jones, B. E. (2005). From waking to sleeping: neuronal and chemical substrates. Trends Pharmacol. Sci. 26, 578-586.

Jones, G. M., and Sugie, N. (1972). Vestibulo-ocular responses in man during sleep. Electroencephalogr. Clin. Neurophysiol. 32, 43-53.

Kaas, J. H. (2000). The reorganization of somatosensory and motor cortex after peripheral nerve or spinal cord injury in primates. Prog. Brain Res. 128, 173-179.

Kasper, J., Diefenhardt, A., Mackert, A., and Thoden, U. (1992). The vestibulo-ocular response during transient arousal shifts in man. Acta Otolaryngol. 112, 1-6.

Kaufman, G. D., Shinder, M. E., and Perachio, A. A. (2000). Convergent properties of vestibular-related brain stem neurons in the gerbil. $J$. Neurophysiol. 83, 1958.

Kirsten, E. B., and Sharma, J. N. (1976). Microiontophoresis of acetylcholine, histamine and their antagonists on neurones in the medial and lateral vestibular nuclei of the cat. Neuropharmacology 15, 743-753.

Kitahara, T., Takeda, N., Kiyama, H., and Kubo, T. (1998). Molecular mechanisms of vestibular compensation in the central vestibular system review. Acta Otolaryngol. Suppl. 539, 19-27.

Lasker, D. M., Hullar, T. E., and Minor, L. B. (2000). Horizontal vestibuloocular reflex evoked by highacceleration rotations in the squirrel monkey. III. Responses after labyrinthectomy. J. Neurophysiol. 83, 2482-2496.

Licata, F., Li Volsi, G., Maugeri, G., Ciranna, L., and Santangelo, F. (1993). Effects of noradrenaline on the firing rate of vestibular neurons. Neuroscience 53, 149-158.

Licata, F., Li Volsi, G., Maugeri, G., and Santangelo, F. (1995). Neuronal responses in vestibular nuclei to dorsal raphe electrical activation. $J$. Vestib. Res. 5, 137-145.

Llinas, R., and Walton, K. (1979). "Vestibular compensation: a distributed property of the central nervous system," in Integration in the Nervous System, eds $\mathrm{H}$. Asanuma and V. J. Wilson (Tokyo: Igaku-Shoin), 145-166.

Llinás, R. R. (1988). The intrinsic electrophysiological properties of mammalian neurons: insights into central nervous system function. Science 242, 1654-1664.

McCarley, R. W. (2007). Neurobiology of REM and NREM sleep. Sleep Med. $8,302-330$.

Menzies, J. R. W., Porrill, J., Dutia, M., and Dean, P. (2010). Synaptic plasticity in medial vestibular nucleus neurons: comparison with computational requirements of $\mathrm{VOR}$ adaptation. PLoS ONE 5, e13182. doi:10.1371/journal.pone.0013182

Miller, D. B., and O'Callaghan, J. P. (2006). The pharmacology of wakefulness. Metab. Clin. Exp. 55, S13-S19.

Mochizuki, T., Yamatodani, A., Okakura, K., Horii, A., Inagaki, N., and Wada, H. (1992). Circadian rhythm of histamine release from the hypothalamus of freely moving rats. Physiol. Behav. 51, 391-394.

Nelson, A. B., Krispel, C. M., Sekirnjak, C., and du Lac, S. (2003). Long-lasting increases in intrinsic excitability triggered by inhibition. Neuron 40, 609-620.

Okamoto, T., Endo, S., Shirao, T., and Nagao, S. (2011). Role of cerebellar cortical protein synthesis in transfer of memory trace of cerebellum- dependent motor learning. J. Neurosci. 31, 8958.

Olabi, B., Bergquist, F., and Dutia, M. B. (2009). Rebalancing the commissural system: mechanisms of vestibular compensation. J. Vestib. Res. 19, 201-207.

Pfanzelt, S., Rössert, C., Rohregger, M., Glasauer, S., Moore, L. E., and Straka, H. (2008). Differential dynamic processing of afferent signals in frog tonic and phasic secondorder vestibular neurons. J. Neurosci. 28, 10349-10362.

Phelan, K. D., and Gallagher, J. P. (1992). Direct muscarinic and nicotinic receptor-mediated excitation of rat medial vestibular nucleus neurons in vitro. Synapse 10, 349-358.

Podda, M. V., Johnston, A. R., Tolu, E., and Dutia, M. B. (2001). Modulation of rat medial vestibular nucleus neurone activity by vasopressin and noradrenaline in vitro. Neurosci. Lett. 298, 91-94.

Rascol, O., Hain, T. C., Brefel, C. Benazet, M., Clanet, M., and Montastruc, J. L. (1995). Antivertigo medications and drug-induced vertigo. A pharmacological review. Drugs 50, 777-791.

Ris, L., Capron, B., de Waele, C., Vidal, P. P., and Godaux, E. (1997). Dissociations between behavioural recovery and restoration of vestibular activity in the unilabyrinthectomized guinea-pig. J. Physiol. (Lond.) $500(\mathrm{Pt}$ 2), 509-522.

Ris, L., Capron, B., Vibert, N., Vidal, P. P., and Godaux, E. (2001a). Modification of the pacemaker activity of vestibular neurons in brainstem slices during vestibular compensation in the guinea pig. Eur. J. Neurosci. 13, 2234-2240.

Ris, L., Hachemaoui, M., Vibert, N., Godaux, E., Vidal, P. P., and Moore, L. E. (2001b). Resonance of spike discharge modulation in neurons of the guinea pig medial vestibular nucleus. J. Neurophysiol. 86, 703-716.

Ris, L., de Waele, C., Serafin, M., Vidal, P. P., and Godaux, E. (1995). Neuronal activity in the ipsilateral vestibular nucleus following unilateral labyrinthectomy in the alert guinea pig. J. Neurophysiol. 74 2087-2099.

Ris, L., and Godaux, E. (1998). Neuronal activity in the vestibular nuclei after contralateral or bilateral labyrinthectomy in the alert guinea pig. J. Neurophysiol. 80 , 2352-2367.

Ris, L., Hachemaoui, M., and Godaux, E. (2002). Effect of labyrinthectomy on the spike generator of vestibular neurons in the guinea pig. Neuroreport 13, 1875-1879.

Rohregger, M., and Dieringer, N. (2003). Postlesional vestibular reorganization improves the gain but impairs the spatial tuning of the maculo-ocular reflex in frogs. J. Neurophysiol. 90, 3736-3749.

Rössert, C., Moore, L. E., Straka, H. and Glasauer, S. (2011). Cellular and network contributions to vestibular signal processing: impact of ion conductances, synaptic inhibition, and noise. J. Neurosci. 31, 8359-8372.

Rössert, C., and Straka, H. (2011). Interactions between intrinsic membrane and emerging network properties determine signal processing in central vestibular neurons. Exp. Brain Res. 210, 437-449.

Sadeghi, S. G., Chacron, M. J., Taylor, M. C., and Cullen, K. E. (2007a). Neural variability, detection thresholds, and information transmission in the vestibular system. J. Neurosci. 27,771 .

Sadeghi, S. G., Minor, L. B., and Cullen, K. E. (2007b). Response of vestibular-nerve afferents to active and passive rotations under normal conditions and after unilateral labyrinthectomy. J. Neurophysiol. 97, 1503-1514.

Saito, Y., and Ozawa, S. (2007). Membrane properties of rat medial vestibular nucleus neurons in vivo. Neurosci. Res. 59, 215-223.

Schuerger, R. J., and Balaban, C. D. (1993). Immunohistochemical demonstration of regionally selective projections from locus coeruleus to the vestibular nuclei in rats. Exp. Brain Res. 92, 351-359.

Schuerger, R. J., and Balaban, C. D. (1999). Organization of the coeruleo-vestibular pathway in rats, rabbits, and monkeys. Brain Res. Brain Res. Rev. 30, 189-217.

Serafin, M., de Waele, C., Khateb, A. Vidal, P. P., and Mühlethaler, M. (1991a). Medial vestibular nucleus in the guinea-pig. I. Intrinsic membrane properties in brainstem slices. Exp. Brain Res. 84, 417-425.

Serafin, M., de Waele, C., Khateb, A., Vidal, P. P., and Mühlethaler, M. (1991b). Medial vestibular nucleus in the guinea-pig. II. Ionic basis of the intrinsic membrane properties in brainstem slices. Exp. Brain Res. $84,426-433$.

Serafin, M., Khateb, A., de Waele, C., Vidal, P. P., and Mühlethaler M. (1990). Low threshold calcium spikes in medial vestibular nuclei neurones in vitro: a role in the generation of the vestibular nystagmus quick phase 
in vivo? Exp. Brain Res. 82, 187-190.

Shao, M., Hirsch, J. C., and Peusner, K. D. (2012). Plasticity of spontaneous excitatory and inhibitory synaptic activity in morphologically-defined vestibular nuclei neurons during early vestibular compensation. J. Neurophysiol. 107, 29-41.

Shimazu, H., and Precht, W. (1965). Tonic and kinetic responses of cat's vestibular neurons to horizontal angular acceleration. J. Neurophysiol. 28, 991-1013.

Shin, M., Moghadam, S. H., Sekirnjak, C., Bagnall, M. W., Kolkman, K. E., Jacobs, R., Faulstich, M., and du Lac, S. (2011). Multiple types of cerebellar target neurons and their circuitry in the vestibulo-ocular reflex. J. Neurosci. 31, 10776-10786.

Shutoh, F., Ohki, M., Kitazawa, H., Itohara, S., and Nagao, S. (2006). Memory trace of motor learning shifts transsynaptically from cerebellar cortex to nuclei for consolidation. Neuroscience 139, 767-777.

Smith, P. F., and Curthoys, I. S. (1989). Mechanisms of recovery following unilateral labyrinthectomy: a review. Brain Res. Brain Res. Rev. 14, 155-180.

Soto, E., and Vega, R. (2010). Neuropharmacology of vestibular system disorders. Curr. Neuropharmacol. 8, 26-40.

Straka, H., Beraneck, M., Rohregger, M., Moore, L. E., Vidal, P.-P., and Vibert, N. (2004). Second-order vestibular neurons form separate populations with different membrane and discharge properties. J. Neurophysiol. 92, 845-861.

Straka, H., Lambert, F. M., Pfanzelt, S., and Beraneck, M. (2009). Vestibuloocular signal transformation in frequency-tuned channels. Ann. N. Y. Acad. Sci. 1164, 37-44.

Straka, H., Vibert, N., Vidal, P. P., Moore, L. E., and Dutia, M. B. (2005). Intrinsic membrane properties of vertebrate vestibular neurons: function, development and plasticity. Prog. Neurobiol. 76, 349-392.

Sun, Y., Waller, H. J., Godfrey, D. A., and Rubin, A. M. (2002). Spontaneous activity in rat vestibular nuclei in brain slices and effects of acetylcholine agonists and antagonists. Brain Res. 934, 58-68.

Takahashi, K., Kayama, Y., Lin, J. S., and Sakai, K. (2010). Locus coeruleus neuronal activity during the sleepwaking cycle in mice. Neuroscience 169, 1115-1126.

Takazawa, T. (2004). Membrane and firing properties of glutamatergic and GABAergic neurons in the rat medial vestibular nucleus. J. Neurophysiol. 92, 3106-3120.

Takeda, N., Morita, M., Horii, A., Nishiike, S., Kitahara, T., and Uno, A. (2001). Neural mechanisms of motion sickness. J. Med. Invest. 48 , 44-59.

Teggi, R., Caldirola, D., Bondi, S., Perna, G., Bellodi, L., and Bussi, M. (2007). Vestibular testing in patients with panic disorder and chronic dizziness. Acta Otorhinolaryngol. Ital. 27, 243-247.

Temporal, S., Desai, M., Khorkova, O., Varghese, G., Dai, A., Schulz, D. J., and Golowasch, J. (2012). Neuromodulation independently determines correlated channel expression and conductance levels in motor neurons of the stomatogastric ganglion. J. Neurophysiol. 107, 718-727.

Thakkar, M. M. (2011). Histamine in the regulation of wakefulness. Sleep Med. Rev. 15, 65-74.

Tighilet, B., and Lacour, M. (1997). Histamine immunoreactivity changes in vestibular-lesioned and histaminergic-treated cats. Eur. J. Pharmacol. 330, 65-77.

Tighilet, B., Mourre, C., Trottier, S., and Lacour, M. (2007). Histaminergic ligands improve vestibular compensation in the cat: behavioural, neurochemical and molecular evidence. Eur. J. Pharmacol. 568, 149-163.
Turrigiano, G. (2011). Too many cooks? Intrinsic and synaptic homeostatic mechanisms in cortical circuit refinement. Annu. Rev. Neurosci. 34 89-103.

Tychsen, L., and Sitaram, N. (1989). Catecholamine depletion produces irrepressible saccadic eye movements in normal humans. Ann. Neurol. 25, 444-449.

Vibert, N., Babalian, A., Serafin, M. Gasc, J. P., Mühlethaler, M., and Vidal, P. P. (1999a). Plastic changes underlying vestibular compensation in the guinea-pig persist in isolated, in vitro whole brain preparations. Neuroscience 93 413-432.

Vibert, N., Bantikyan, A., Babalian, A., Serafin, M., Mühlethaler, M., and Vidal, P. P. (1999b). Post-lesional plasticity in the central nervous system of the guinea-pig: a "top-down" adaptation process? Neuroscience 94, $1-5$

Vibert, N., Beraneck, M., Bantikyan, A., and Vidal, P. P. (2000). Vestibular compensation modifies the sensitivity of vestibular neurones to inhibitory amino acids. Neuroreport 11, 1921-1927.

Vibert, N., Serafin, M., Vidal, P.P., and Mühlethaler, M. (1994). "Pharmacological properties of medial vestibular neurones in the guinea-pig in vitro," in Information Processing Underlying Gaze Control Pergamon Studies in Neuroscience (New York: Elsevier Science), 159-173.

Vidal, P. P., Vibert, N., Serafin, M., Babalian, A., Mühlethaler, M., and de Waele, C. (1999). Intrinsic physiological and pharmacological properties of central vestibular neurons. Adv. Otorhinolaryngol. 55, 26-81.

Wang, H., Brozoski, T. J., and Caspary, D. M. (2011). Inhibitory neurotransmission in animal models of tinnitus: maladaptive plasticity. Hear. Res. 279, 111-117
Waxman, S. G., and Hains, B. C. (2006). Fire and phantoms after spinal cord injury: $\mathrm{Na}+$ channels and central pain. Trends Neurosci. 29, 207-215.

Yamanaka, T., Him, A., Cameron, S. A., and Dutia, M. B. (2000). Rapid compensatory changes in GABA receptor efficacy in rat vestibular neurones after unilateral labyrinthectomy. J. Physiol. (Lond.) 523(Pt 2), 413-424.

Yardley, L., Watson, S., Britton, J., Lear, S., and Bird, J. (1995). Effects of anxiety arousal and mental stress on the vestibulo-ocular reflex. Acta Otolaryngol. 115, 597-602.

Zeitzer, J. M., Kodama, T., Buckmaster, C. L., Honda, Y., Lyons, D. M., Nishino, S., and Mignot, E. (2011) Time-course of cerebrospinal fluid histamine in the wake-consolidated squirrel monkey. J. Sleep Res. doi: 10.1111/j.1365-2869.2011.00957.x

Conflict of Interest Statement: The authors declare that the research was conducted in the absence of any commercial or financial relationships that could be construed as a potential conflict of interest.

Received: 02 December 2011; paper pending published: 15 December 2011; accepted: 09 February 2012; published online: 28 February 2012.

Citation: Beraneck $M$ and Idoux $E$ (2012) Reconsidering the role of neuronal intrinsic properties and neuromodulation in vestibular homeostasis. Front. Neur. 3:25. doi: 10.3389/fneur.2012.00025

This article was submitted to Frontiers in Neuro-otology, a specialty of Frontiers in Neurology.

Copyright (c) 2012 Beraneck and Idoux. This is an open-access article distributed under the terms of the Creative Commons Attribution Non Commercial License, which permits non-commercial use, distribution, and reproduction in other forums, provided the original authors and source are credited. 